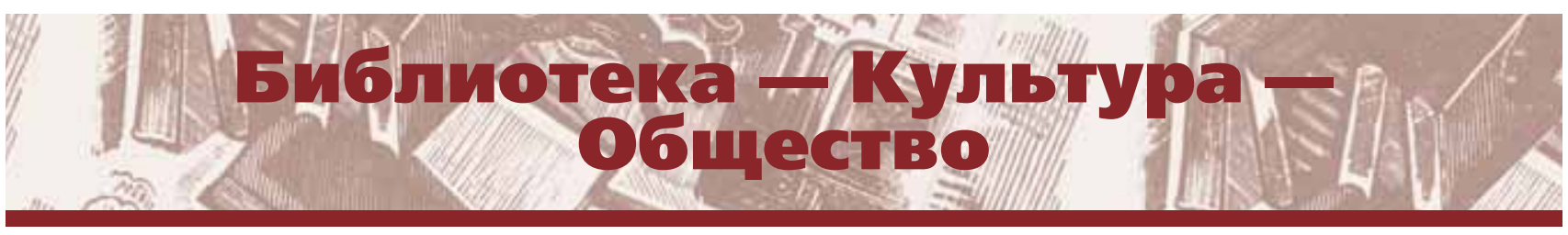

УДК 021.84

ББК 78.352

DOI 10.25281/0869-608X-2018-67-6-607-615

\title{
H.A. CAXAPOB
}

\section{Функционирование системы обязательного экземпляра и пути ее совершенствования}

Реферат. Система обязательного экземпляра (ОЭ), по-прежнему являющаяся главным источником формирования национального библиотечно-информационного фонда документов Российской Федерации, нуждается в дальнейшем развитии и совершенствовании. Цель настоящей статьи выделить основные проблемы, с которыми сталкивается современная система ОЭ в сегменте обязательного федерального экземпляра печатных изданий и рассмотреть различные варианты их решения. Одна из главных проблем - неполная доставка (или недоставка) производителями документов издаваемых ими печатных изданий, особенно в электронной форме, хотя этого требует ныне действующая редакция Федерального закона «Об обязательном экземпляре документов». Вместо положенных по закону 16 экз. многие издатели доставляют в Российскую книжную палату (РКП, филиал ИТАР-ТАСС) меньшее их число, вплоть до 1 экземпляра. Особенно тревожная ситуация складывается с поставкой изданий, выпускаемых малыми тиражами, немало сложностей и с поставкой периодики, в том числе газет.

Общие нормы закона «Об обязательном экземпляре документов» распространены также на экземпляры печатных изданий в электронной форме. Включение их в состав ОЭ повлекло за собой значительные перемены и для производителей документов, и для организаций - получателей ОЭ. В 2017 г. лишь 518 из 5775 российских издательств прислали в РКП ОЭ печатных изданий в электронной форме. Общее число присланных электронных экземпляров составило 24,5 тыс. (около $21 \%$ от числа всех выпущенных в стране изданий в традиционной печатной форме).

Существуют различные пути решения возникших проблем. Библиотеки-получатели постоянно ставят вопрос о необходимости усиления ответственности производителей документов за неполную доставку или недоставку ОЭ. В настоящее время в Российской государственной библиотеке (РГБ) разработана и обнародована «Декларация РГБ о работе с обязательным экземпляром печатного издания в электронной форме», в которой разъясняются важнейшие принципы работы РГБ как оператора Национальной электронной библиотеки с обязательными экземплярами. Рассматриваются ряд предложений, в частности РКП, Библиотеки Российской академии наук, Фундаментальной библиотеки Института научной информации по общественным наукам, по совершенствованию системы ОЭ. Делается вывод о необходимости принятия действенных мер по обеспечению полной и своевременной доставки документов от их производителей, поэтапного включения в состав ОЭ новых документов, существующих только в электронной сфере.

Ключевые слова: обязательный экземпляр документов, система обязательного экземпляра, обязательный экземпляр печатных изданий в

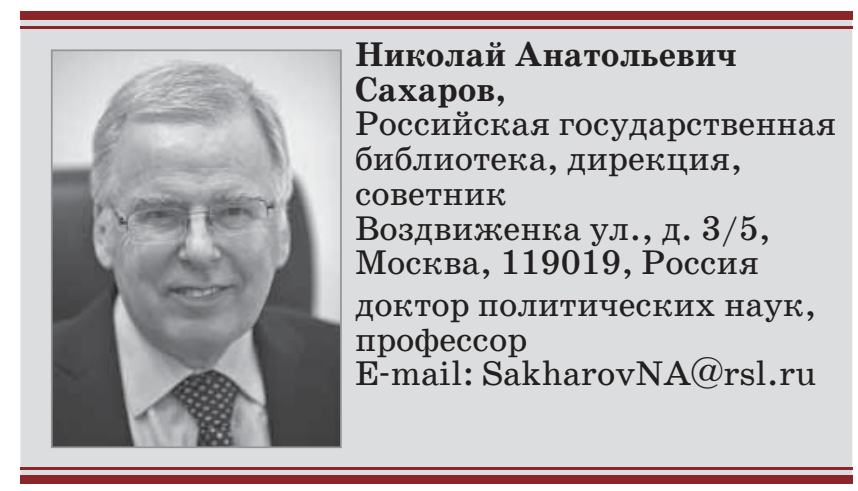


электронной форме, производители документов, Российская государственная библиотека, Российская книжная палата, получатели обязательного экземпляра, Национальная электронная библиотека, книжный фонд.

Для цитирования: Сахаров Н.A. Функционирование системы обязательного экземпляра и пути ее совершенствования // Библиотековедение. 2018. T. 67, № 6. С. 607-615. DOI: 10.25281/0869608X-2018-67-6-607-615.

$0^{1}$ истема обязательного экземпляра в нашей стране, как убедительно показал анализ ее современного состояния, попрежнему является главным источником и ресурсной базой наполнения национального библиотечно-информационного фонда документов Российской Федерации [1]. В условиях, когда библиотеки не получают достаточных ассигнований на приобретение издаваемых печатных изданий, именно система обязательного экземпляра позволяет в целом удовлетворять потребности пользователей российских библиотек. Цель настоящей статьи - выделить основные проблемы, с которыми сталкивается современная система ОЭ в сегменте обязательного федерального экземпляра печатных изданий и рассмотреть различные варианты их решения.

В настоящее время, как и во все исторические эпохи [2; 3], одной из главных является проблема неполной доставки (или недоставки) производителями документов - издательствами издаваемых ими печатных изданий, особенно в электронной форме, как того требует ныне действующая редакция Федерального закона «Об обязательном экземпляре документов» [4]. Именно на это прежде всего указывают многие библиотечно-информационные организации получатели обязательных федеральных экземпляров печатных изданий. Вместо положенных по закону 16 экз. многие издатели доставляют в Российскую книжную палату (РКП, филиал ИТАР-ТАСС) меньшее их число, вплоть до 1 экз., что лишает РКП возможности в полном объеме распределять эти издания между библиотеками и другими организациями-получателями.

Ранее производители печатных изданий (а это были, прежде всего, государственные типографии) неукоснительно выполняли нормы закона по поставке положенного количества обязательных экземпляров (ОЭ). Теперь же, когда деятельность издательств в Российской Федерации не лицензируется, многие из них, ссылаясь на сложные финансовые обстоятельства в условиях рыночной экономики, посылают в РКП то количество ОЭ, которое они считают нужным (некоторые не доставляют ни одного экземпляра). В результате, когда какое-либо издательство направляет в РКП всего лишь 1 экз. выпущенного им издания, то его название заносится в Государственную регистрацию отечественных произведений печати, но не доходит ни до одной из библиотек - получателей ОЭ [1, с. 492], официально утвержденных соответствующим нормативно-правовым документом.

Необходимо отметить, что в последние годы случаи недопоставки (непоставки) ОЭ в РКП переросли в устойчивое и масштабное явление. По различным экспертным оценкам, ежегодно РКП, а значит и библиотеки, недополучает $15-20 \%$ всей книжной продукции, издаваемой в Российской Федерации в течение года [5, с. $73 ; 6$, с. 17]. Согласно данным РКП, приведенным в изданном в 2018 г. ежегодном докладе Федерального агентства по печати и массовым коммуникациям (Роспечати), в 2017 г. было выпущено 117359 наименований книг и брошюр [7, с. 7]. Таким образом, число печатных изданий, недополученных РКП и библиотеками, может достигать десятков тысяч единиц. Это - серьезный удар как по текущему формированию национального библиотечно-информационного фонда Российской Федерации, так и по интересам пользователей библиотек.

Особенно тревожная ситуация складывается с поставкой изданий, выпускаемых малыми тиражами: «..более половины наименований $(55,1 \%)$ всех книг и брошюр, издаваемых в стране, выпускается тиражом менее 1000 экземпляров. При этом еще десять лет назад доля изданий, выходивших тиражом менее 1000 экземпляров, едва превышала 40\% » [7, с. 9]. Здесь обязательно следует добавить, что в таком сегменте отечественных печатных изданий, как научная и образовательная литература, тиражи стали еще меньше и составляют 500, 300, 100 и менее экземпляров. По последним данным, средний тираж научной книги в 2017 г. составлял 369 экз., а учебной литературы для вузов - 210 экз. [8, с. 129]. Между тем именно малотиражные научно-образовательные издания часто не попадают в РКП и, соответственно, в библиотеки- получатели, а ведь именно в этих изданиях содержатся сведения о многих важных научных исследованиях и образовательных программах. 
В отечественном книгоиздании сложилась еще одна практика, прямо затрагивающая библиотеки - получатели ОЭ и их пользователей. Как отмечает Государственная публичная научно-техническая библиотека Сибирского отделения Российской академии наук (ГПНТБ СО $\mathrm{PAH})^{1}$, многие подготовленные в ряде российских вузов научные и образовательные издания изначально не предназначаются для общедоступного книжного рынка. Они издаются только в электронной форме и распространяются исключительно по внутривузовским корпоративным сетям.

Библиотеки, специализирующиеся преимущественно на комплектовании современной научной литературой, обоснованно поднимают вопрос о недополучении многих изданий, входящих в категорию научной периодики. Так, ГПНТБ СО РАН представила обширный перечень из 57 названий периодических изданий, которые фрагментарно поступают в эту крупнейшую библиотеку Сибирского региона, например: «Актуальные проблемы социально-экономического развития России», «Информационные и телекоммуникационные технологии», «Проблемы управления рисками в техносфере», «Наносистемы: физика, химия, математика» и др. И еще один факт: Библиотека по естественным наукам Российской академии наук (БЕН РАН) только в 2017 г. недополучила по линии обязательного федерального экземпляра 1088 журналов (см. примеч. 1). Значимость этих и других научных журналов весьма велика и они, безусловно, должны быть полно представлены в специализированных библиотечных фондах нашей страны.

Помимо проблем с получением по линии федерального обязательного экземпляра научной периодики, в настоящее время имеется немало сложностей и с поставкой периодики вообще, в том числе газет. Библиотеки указывают на то, что в последние годы происходят большие задержки с получением газет как обязательных экземпляров из РКП, которая, по их мнению, слишком долго эти газеты обрабатывает. В то же время в саму РКП многие газеты приходят с большим опозданием, и случается, что некоторые из них поступают сразу месячными комплектами. В этих условиях библиотеки, чтобы удовлетворить спрос на газеты, приобретают некоторые из них по подписке. Однако средства на эти цели у библиотек, даже крупных, очень ограничены. Так, по данным Российской национальной библиотеки (РНБ), доля газет, приобретаемых ею по подписке, составляет не более $5 \%$ от общего числа газет в РНБ (см. примеч. 1).
Приходится констатировать: закон «Об обязательном экземпляре документов» в части сроков доставки изданий и количестве доставляемых ОЭ исполняется весьма неудовлетворительно, особенно в части доставки ОЭ печатных изданий в электронной форме. Т.В. Петрусенко и И.В. Эйдемиллер указывают, что «у издателей отсутствует достаточная мотивация для его исполнения» [9, с. 219].

Общие нормы закона «Об обязательном экземпляре документов" распространены также и на экземпляры печатных изданий в электронной форме [10, с. 13]. Включение их в состав ОЭ повлекло за собой значительные перемены и для производителей документов, и для организаций - получателей ОЭ. Законом установлено (ст. 7, п. 2.1):

«производители документов в течение семи дней со дня выхода в свет первой партии тиража печатных изданий доставляют с использованием информационнотелекоммуникационных сетей по одному обязательному экземпляру печатных изданий в электронной форме, заверенному квалифицированной электронной подписью производителя документов, в Информационное телеграфное агентство России (ИТАР-ТАСС) и в Российскую государственную библиотеку» [4].

Диссертации, также входящие в состав ОЭ и относящиеся к неопубликованным документам, должны поступать в электронной форме, заверенные квалифицированной электронной подписью производителя документов (диссертационных советов) в 30 -дневный срок со дня защиты диссертации и присуждения ученой степени. При этом экземпляры диссертаций в электронной форме доставляются: по всем научным специальностям в Центр информационных технологий и систем органов исполнительной власти (ЦИТИС) - орган научно-технической информации федерального органа исполнительной власти в сфере научной, научно-технической и инновационной деятельности и в Российскую государственную библиотеку (РГБ), а по медицине и фармацевтике - в Центральную научную медицинскую библиотеку [11].

Все указанные новые нормы закона «Об обязательном экземпляре документов» вступили в силу с 1 января 2017 г., но еще задолго до этой даты руководители многих крупнейших издательств начали выражать свое несогласие, особенно в связи с возложенной на них 
Поступление обязательного экземпляра в Российскую государственную библиотеку

\begin{tabular}{|c|c|c|c|c|}
\hline \multirow[b]{2}{*}{ Период } & \multicolumn{3}{|c|}{ Количество наименований печатных книг } & \multirow{2}{*}{$\begin{array}{l}\text { Число издательств, направивших } 0 Э \\
\text { печатных изданий в электронной форме }\end{array}$} \\
\hline & всего & $\begin{array}{l}\text { в электронной } \\
\text { форме }\end{array}$ & доля $(\%)$ & \\
\hline 2017 & 110720 & 5016 & 4,5 & 2303 \\
\hline $2018 *$ & 111417 & 8273 & 7,4 & 4713 \\
\hline
\end{tabular}

* По состоянию на 19.11.2018 г.

обязанностью доставки ОЭ печатных книг и периодики в электронной форме.

Суть этих претензий сводится к следующему. Во-первых, утверждается, что направление издательствами в РГБ в качестве обязательных экземпляров печатных изданий в электронной форме создает реальную возможность для их незаконного копирования, что нанесет значительный ущерб правообладателям и создаст прямую угрозу для всей книжной индустрии в стране. Во-вторых, заявляется, что многие технологические элементы процесса доставки печатного экземпляра в электронной форме (изготовление файла с достаточно высоким уровнем разрешения, необходимость его заверения квалифицированной электронной цифровой подписью производителя) являются весьма затратными и обременительными для издательств, особенно небольших [12].

В итоге многие издательства не доставляют ОЭ печатных изданий в электронной форме в РКП и РГБ. По данным отраслевого доклада «Книжный рынок России. Состояние, тенденции и перспективы развития» за 2017 г. лишь 518 из 5775 издательств, действовавших в Российской Федерации, прислали в РКП ОЭ печатных изданий в электронной форме в 2017 году. Общее число присланных электронных экземпляров составило 24,5 тыс., т. е. около $21 \%$ от числа всех выпущенных в стране изданий в традиционной печатной форме [7, с. 18].

В РГБ в 2017 г. доля поступления наименований ОЭ в электронной форме составила всего $4,5 \%$ от общего числа наименований печатных книг, периодических изданий $-6,5 \%$ от общего числа поступлений периодики. Очевидно, что подобная ситуация является явно ненормальной и серьезно препятствует эффективному функционированию системы обязательного экземпляра в нашей стране. В 2018 г. объемы поступлений немного возросли (см. табл.). Следует отметить позитивную тенденцию повышения в 2018 г. исполнительской дисциплины издательств, выросло число зарегистрированных личных кабинетов издателя для постав- ки электронных копий печатного экземпляра. В итоге по последним имеющимся данным 4713 издательств Российской Федерации отправляют свои ОЭ в электронной форме в РГБ 2 .

\section{Варианты решения проблем}

В сложившейся ситуации обсуждаются различные пути решения возникших проблем. Библиотеки-получатели постоянно ставят вопрос о необходимости усиления ответственности производителей документов за неполную доставку или недоставку ОЭ.

В законе «Об обязательном экземпляре документов» имеется ст. 23 «Ответственность за нарушение порядка доставки обязательного экземпляра», которая гласит:

«За недоставку, несвоевременную или неполную доставку обязательного экземпляра производители документов несут ответственность в соответствии с законодательством Российской Федерации об административных правонарушениях» [4].

А Кодекс об административных правонарушениях Российской Федерации статья 13.23 предусматривает, что нарушение установленного законом порядка предоставления, в частности обязательного экземпляра документов, влечет наложение административного штрафа на граждан в размере от 200 до 500 руб., на должностных лиц - от 1 до 2 тыс. руб., на юридических лиц - от 10 до 20 тыс. руб. [13]. Такие штрафы не могут быть существенными для многих издательств или редакций газет. Поэтому есть предложения в разы увеличить размеры штрафов за нарушение производителями порядка доставки документов в части срока доставки и количества доставляемых документов.

Имеются и другие подходы. В настоящее время в РГБ под руководством генерального директора В.В. Дуды разработан и обнародован важный документ - «Декларация РГБ о 
работе с обязательным экземпляром печатного издания в электронной форме», в которой разъясняются важнейшие принципы работы РГБ как оператора Национальной электронной библиотеки (НЭБ) с обязательными экземплярами:

В связи с вступившими в силу 1 января 2017 г. изменениями Федерального закона от 29 декабря 1994 г. № 77-ФЗ «Об обязательном экземпляре документов» Российская государственная библиотека как оператор ГИС НЭБ разъясняет принципы работы с обязательным экземпляром печатного издания в электронной форме.

1. Обязательный экземпляр печатного издания в электронной форме, после доставки в РГБ и надлежащей технической и библиографической обработки, поступает на постоянное хранение в электронную библиотеку РГБ и с этого момента считается включенным в НЭБ, также с целью постоянного хранения.

2. Безвозмездное использование обязательного экземпляра допускается исключительно посредством электронной библиотеки РГБ на стационарных компьютерах в помещениях читальных залов РГБ.

3. Любое иное безвозмездное использование обязательного экземпляра, в том числе в виртуальных читальных залах РГБ, исключено.

4. Средства технической защиты, используемые в РГБ, полностью исключают возможность несанкционированного доступа к экземпляру, а также создание копии в электронном виде.

5. Понятия «включение» (хранение) и «использование» в НЭБ обязательных экземпляров строго разграничены, в соответствии с Указанием Президента Российской Федерации от 17 февраля 2018 г. № ПР-294.

6. Использование обязательных экземпляров в НЭБ осуществляется только после отбора экспертными советами НЭБ в соответствии с профилем НЭБ и только после заключения лицензионных договоров с издателями, авторами и иными правообладателями.

7. Оплата за использование обязательных экземпляров в НЭБ будет осуществляться как за счет средств пользователей, так и за счет специально выделяемых государственных средств, исходя из статистики использования.

8. Перечисленные выше принципы будут зафиксированы в «Положении о НЭБ», над разработкой которого сегодня совместно работают Администрация Президента РФ, Минкультуры России, РГБ, Российский книжный союз и издательское сообщество в целом.

Российская государственная библиотека нацелена на открытость, сотрудничество и диалог с сообществом издателей, авторов и иных правообладателей [14].

Комплекс предложений, направленных на реформирование системы обязательного экземпляра, особенно в части обязательного федерального экземпляра печатных изданий, выдвинула РКП (филиал ИТАР-ТАСС) [15]. Центральное место занимает предложение о введении «Единого окна». Если в ныне действующем законе предусматривается, что ОЭ печатного издания в электронной форме направляется в ИТАРТАСС и РГБ (т. е. в «два окна»), то теперь предлагается направлять электронный файл только в ИТАР-ТАСС. Предлагается ввести новые понятия: первичный получатель ОЭ и вторичный получатель ОЭ [15, с. 7]. При такой схеме к первичным получателям будет относиться ИТАРTACC, а все остальные, т. е. библиотеки и другие организации-получатели, станут вторичными получателями. Более того, предлагается организациям-получателям самим скачивать файлы обязательных печатных изданий с сервера ИТАР-ТАСС или из предлагаемой ИТАР-ТАСС Государственной информационной системы по контролю за доставкой и использованием обязательного экземпляра документов (ГИС СОЭД).

РКП активно продвигает предложение о том, чтобы в современных условиях ОЭ включал в себя самые различные электронные публикации. Это предложение отвечает потребностям современной эпохи и находится в русле общемировых тенденций. Так, в «Руководстве по законодательству об обязательном экземпляре», изданном при поддержке ЮНЕСКО и ИФЛА, отмечается:

«Безотносительно к выдвигаемым доводам и всем ожидаемым технологическим проблемам, в принципе все электронные публикации, как автономные, так и онлайновые, должны быть объектом обязательного экземпляра» [16, с. 31].

Также РКП поднимает вопрос о так называемых малотиражных изданиях (менее 100 или 50 экз.), предлагая, во-первых, сократить количество ОЭ малотиражной продукции, во-вторых, экземпляры изданий со сверхмалыми тиражами в электронной форме сосредоточить только в РКП. 
В связи с предложениями, исходящими от РКП, и осуществлением ею функции по распределению ОЭ между организациями-получателями представляет интерес опыт Республики Беларусь. Национальная книжная палата (НКП) Беларуси, подобно РКП, является центром государственной библиографии и учета издательской продукции, ведет систему государственной библиографической информации, выступает в качестве головной организации по разработке технических нормативных актов в сфере издательского дела. Кроме того, через НКП Беларуси происходит присвоение новым изданиям номера международного стандарта книжной продукции (ISBN). Наконец, НКП Беларуси получает один ОЭ всех книг, издаваемых в стране, и выполняет функции государственного фондохранилища печатных изданий Беларуси [17]. Однако в отличие от РКП, НКП Беларуси не уполномочена распределять ОЭ между организациями-получателями. Эти организации, в число которых входят ведущие белорусские библиотеки и ряд государственных учреждений, получают ОЭ печатных изданий непосредственно от издательств (и они, за редчайшим исключением, исправно выполняют эту обязанность).

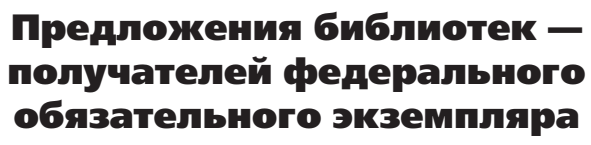

Отечественные библиотеки - получатели федерального ОЭ также выдвигают конкретные предложения по совершенствованию системы ОЭ в нашей стране.

Так, Библиотека Российской академии наук (БАН) предлагает ряд мер, призванных повысить эффективность использования ОЭ (см. примеч. 1). Она готова взять на себя функции коллектора-распределителя той части отечественной литературы, которая не совпадает с профилем ее комплектования, в частности литературы для детей и юношества. После определенного изменения уставных и организационных документов БАН могла бы заключить договоры о сотрудничестве с различными библиотеками Санкт-Петербурга и Северо-Западного федерального округа о передаче оговоренного репертуара изданий из федерального ОЭ и осуществить научно-методическую помощь по организации точек доступа.

Фундаментальная библиотека Института научной информации по общественным на- укам (ФБ ИНИОН) РАН обращается с настоятельной просьбой возвращения ей статуса учреждения - получателя авторефератов диссертаций по гуманитарным наукам (в течение многих десятилетий авторефераты этого профиля поступали). При этом особое внимание ФБ ИНИОН обращает на значимость авторефератов диссертаций для формирования информационных ресурсов в области социальных и гуманитарных наук (см. примеч. 1).

Дальневосточная государственная научная библиотека (ДГНБ) просит включить в комплект получаемых ею изданий по линии федерального ОЭ изоиздания, нотные издания, географические карты и атласы на русском языке. Особую заинтересованность ДГНБ проявляет к нотным изданиям, поскольку в Хабаровске имеется целый ряд образовательных учреждений культуры - Хабаровский краевой колледж искусств, Хабаровский государственный институт искусств и культуры, музыкальные школы, музыкальные студии и др.

В конце 2017 г. в перечень организаций получателей федерального ОЭ были включены ведущие библиотеки нового субъекта Российской Федерации: Крымская республиканская универсальная научная библиотека им. И.Я. Франко и Крымская республиканская детская библиотека им. В.Н. Орлова. На протяжении, по крайней мере, первой половины 2018 г. эти библиотеки не получали от РКП издания по тематике «Краеведение и этнография Крыма» (см. примеч. 1).

Все предложения и пожелания от библиотек - получателей ОЭ печатного издания заслуживают внимательного рассмотрения.

В целом система ОЭ в Российской Федерации нуждается в дальнейшем совершенствовании [18], но не в пересмотре и тем более сломе ее фундаментальных основ. Необходимо принять действенные меры по обеспечению полной и своевременной доставки документов от их производителей, поэтапно включать в состав ОЭ новые документы, существующие только в электронной сфере.

Особое значение в условиях начавшейся цифровой эпохи имеет задача по аккумулированию печатных изданий в электронной форме. Данное в начале 2018 г. поручение Президента Российской Федерации В.В. Путина по дальнейшему развитию НЭБ предусматривает в том числе обеспечение включения в НЭБ электронных копий $100 \%$ российских изданий на правах ОЭ [19]. Это предсказуемо вызвало активное обсуждение в библиотечном и издательском сообществах. Добиться реализации президентско- 
го поручения будет непросто, но это позволит нашей стране располагать еще одним важным электронным ресурсом для дальнейшего продвижения вперед.

\section{Примечания}

1 Сведения получены из опроса, проведенного автором летом 2018 г. среди библиотечно-информационных организаций и получателей обязательного федерального экземпляра печатных изданий.

2 Данные действующего в РГБ отдела организации и функционирования фонда электронной библиотеки.

\section{Список источников}

1. Сахаров Н.A. Система обязательного экземпляра в России: этапы развития и современное состояние / Библиотековедение. 2018. Т. 67, № 5. C. 487-499. DOI: 10.25281/0869-608X2018-67-5-487-499.

2. Самарин А.Ю. Типографщики и книгочёты : очерки по истории книги в России второй половины XVIII века / Российская гос. б-ка. 2-е изд., испр. и доп. Москва : Пашков дом, 2015. 414 с.

3. Самарин А.Ю. Происхождение системы обязательного экземпляра в России: новые архивные данные / / Библиография. 2007. № 1. С. 92-97.

4. Федеральный закон от 29.12.1994 г. № 77-ФЗ «Об обязательном экземпляре документов» [Электронный ресурс] // Президент России. URL: http://kremlin.ru/acts/bank/7384 (дата обращения: 31.05.2018).

5. Тихонова Л.Н. Комплектование фондов научных библиотек // Библиография и книговедение. 2017. № 4. С. 72-75.

6. НЭБ: перезагрузка. Что дальше? // Университетская книга. 2018. № 4. С. 16-21.

7. Книжный рынок России. Состояние, тенденции и перспективы развития : отраслевой доклад / под общ. ред. В.В. Григорьева. Москва : Федеральное агентство по печати и массовым коммуникациям, 2018. 89 с.

8. Цветкова B.A. Научное книгоиздательство в России: кризис или смена парадигмы? // Библиотековедение. 2018. Т. 67, № 2. С. 127 136. DOI: 10.25281/0869-608X-2018-67-2127-136.

9. Петрусенко Т.В., Эйделиллер И.В. Обязательный экземпляр документов в РНБ: от Императорской публичной к Российской на- циональной библиотеке // Российская книжная палата: славное прошлое и надежное будущее : материалы науч.-метод. конф. к 100-летию РКП. Москва : Российская книжная палата, 2017. С. 195-223.

10. Федеральный закон от 3 июля 2016 г. № 278-ФЗ «О внесении изменений в Федеральный закон “Об обязательном экземпляре документов” " // Российская газета. 2016. 8 июля. № 7017 (149).

11. Сахаров Н.А. Система обязательного экземпляра в Российской Федерации: развитие и обновление // Библиотековедение. 2016. T. 65, № 5. C. 493-498. DOI: 10.25281/0869608X-2016-65-5-493-498.

12. Электронный ОЭ: хранить нельзя использовать // Университетская книга. 2017. № 4. С. $13-19$.

13. Статья 13.23. Нарушение порядка представления обязательного экземпляра документов, письменных уведомлений, уставов и договоров [Электронный ресурс] // Кодекс об административных нарушениях Российской Федерации. URL: http://www.kodap.ru/razdel-2/glava-13/ st-13-23-koap-rf (дата обращения: 16.10.2018).

14. Декларация о работе с обязательным экземпляром печатного издания в электронной форме [Электронный ресурс] // Российская государственная библиотека. URL: https:// www.rsl.ru/ru/all-news/neb-oe-declaration (дата обращения: 16.10.2018).

15. Зотов П.А. Концепция системы обязательного экземпляра документов // Библиография и книговедение. 2018. № 3. С. 5-18.

16. Ларивьер Ж. Руководство по законодательству об обязательном экземпляре / [пер. с англ. И.Ю. Багровой]. Москва : Пашков дом, 2002. $88 \mathrm{c}$.

17. Национальная книжная палата Беларуси [Электронный ресурс]. URL: https://natbook. org.by/ (дата обращения: 16.10.2018).

18. Сухоруков К.M. Обязательный экземпляр документов сегодня и завтра // Библиография и книговедение. 2018. № 3. С. 3-4.

19. Национальные проекты: современное состояние и перспективы развития : материалы пленарной дискуссии [Электронный ресурс] // VIII Всероссийская научно-практическая конференция "Фонды библиотек в цифровую эпоху: традиционные и электронные ресурсы, комплектование, использование», 26-30 марта 2018 г., Санкт-Петербург : материалы. URL: http://nlr.ru/tus/20180326/ program.html (дата обращения: 16.10.2018). 


\title{
Operation of Legal Deposit System and the Ways of Its Improvement
}

\author{
Nikolay A. Sakharov, \\ Russian State Library, 3/5 Vozdvizhenka Str., Moscow, 119019, Russia \\ E-mail: SakharovNA@rsl.ru
}

\begin{abstract}
Legal deposit (LD) system, which remains to be the main source of formation of the national library-information stock of documents of the Russian Federation, needs further development and improvement. The purpose of this article is to identify the main problems faced by the modern system of LD in the segment of Federal legal deposit copy of printed publications and to consider various solutions. One of the main problems is incomplete delivery (or non-delivery) by manufacturers of the documents of printed publications issued by them, especially in electronic form, although this is required by the current version of the Federal law "On Legal Deposit copy of documents". Instead of 16 copies, set by the Law, many publishers deliver to the Russian Book Chamber (RBC, ITAR-TASS branch) a smaller number of them, up to one copy. Situation with the delivery of publications produced in small runs is particularly alarming, as well as there are certain difficulties with the delivery of periodicals, including newspapers.

General provisions of the Law "On Legal Deposit copy of documents" also apply to the copies of printed publications in electronic form. Their inclusion in the LD has led to significant changes for both document producers and LD recipient organizations. In 2017, only 518 of 5775 Russian publishers sent to the RBC the LD copies of printed publications in electronic form. The total number of electronic copies sent amounted to 24.5 thousand (about $21 \%$ of all publications issued in the country in traditional printed form).

There are different ways to solve the arisen problems. The libraries-recipient constantly put the question on the need to strengthen the responsibility of manufacturers of documents for the incomplete or undelivered LD. Currently, the Russian State Library (RSL) has developed and published the "Declaration of the RSL on the work with Legal Deposit copy of the printed publication in electronic form", which explains the most important principles of work with LD of the RSL as the operator of the National Electronic Library. The article considers a number of proposals on improvement of the LD system, in particular, of the RBC, the Library of the Russian Academy of Sciences, the Fundamental Library of the Institute of Scientific Information on Social Sciences. The author concludes that it is necessary to take effective measures to ensure the complete and timely delivery of documents from their manufacturers and stepwise inclusion in the LD of new documents that exist only in the electronic form.
\end{abstract}

Key words: Legal Deposit Copy of Documents, Legal Deposit System, Legal Deposit Copy of Printed Publications in Electronic Form, Producers of Documents, Russian State Library, Russian Book Chamber, Recipients of Legal Deposit, National Electronic Library, Book Stock.

Citation: Sakharov N.A. Operation of Legal Deposit System and the Ways of Its Improvement, Bibliotekovedenie [Library and Information Science (Russia)], 2018, vol. 67, no. 6, pp. 607-615. DOI: 10.25281/0869-608X-2018-67-6-607-615.

\section{References}

1. Sakharov N.A. Legal Deposit System in Russia: Stages of Development and Contemporary State, Bibliotekovedenie [Library and Information Science (Russia)], 2018, vol. 67, no. 5, pp. 487-499 (in Russ.). DOI: 10.25281/0869-608X-2018-675-487-499.

2. Samarin A.Yu. Tipografshchiki i knigochety: ocherki po istorii knigi $v$ Rossii vtoroi poloviny
XVIII veka [The Book Printers and Book Readers: Essays on the History of Book in Russia in the Latter Half of the 18th Century]. Moscow, Pashkov Dom Publ., 2015, 414 p.

3. Samarin A.Yu. The Origin of the Legal Deposit System in Russia: New Archival Data, Bibliografiya [Bibliography], 2007, no. 1, pp. 92-97 (in Russ.). 
4. Federal Law of 29.12.1994 № 77-FZ “On Legal Deposit Copy of Documents", Prezident Rossii [President of Russia]. Available at: http://kremlin.ru/acts/bank/7384 (accessed 31.05.2018) (in Russ.).

5. Tikhonova L.N. Acquisitions in Scientific Libraries, Bibliografiya i knigovedenie [Bibliography and Bibliology], 2017, no. 4, pp. 72-75 (in Russ.).

6. National Digital Library: Reloaded. What Is Next? Universitetskaya kniga [University Book], 2018, no. 4, pp. 16-21 (in Russ.).

7. Grygoryev V.V. (ed.) Knizhnyi rynok Rossii. Sostoyanie, tendentsii i perspektivy razvitiya: otraslevoi doklad [Russian Book Market. Current State, Trends and Development Prospects: industry report]. Moscow, Federal'noe Agentstvo po Pechati i Massovym Kommunikatsiyam Publ., 2018, 89 p.

8. Tsvetkova V.A. Scientific Book Publishing in Russia: Crisis or Paradigm Shift? Bibliotekovedenie [Library and Information Science (Russia)], 2018, vol. 67, no. 2, pp. 127-136 (in Russ.). DOI: 10.25281/0869-608X-2018-67-2-127-136.

9. Petrusenko T.V., Eidemiller I.V. Legal Deposit of Documents in the NLR: From the Imperial Public to the National Library of Russia, Rossiiskaya knizhnaya palata: slavnoe proshloe $i$ nadezhnoe budushchee: materialy nauch.-metod. konf. k 100-letiyu RKP [Russian Book Chamber: The Glorious Past and Reliable Future: Proceedings of the Sci.-Method. Conf. to the 100th Anniversary of the Russian Book Chamber]. Moscow, Rossiiskaya Knizhnaya Palata Publ., 2017, pp. 195-223 (in Russ.).

10. Federal Law of July 3, 2016, № 278-FZ “On Amending the Federal Law 'On Legal Deposit Copy of Documents'", Rossiiskaya gazeta [Russian Gazette], 2016, July 8, no. 7017 (149) (in Russ.).

11. Sakharov N.A. The Legal Deposit System in the Russian Federation: Development and Updating, Bibliotekovedenie [Library and Information Science (Russia)], 2016, vol. 65, no. 5, pp. 493-498 (in Russ.). DOI: 10.25281/0869608X-2016-65-5-493-498.
12. Electronic Legal Deposit Copy: Cannot Be Stored/Used, Universitetskaya kniga [University Book], 2017, no. 4, pp. 13-19 (in Russ.).

13. Article 13.23. Violation of the Procedure of Submission of a Legal Deposit Copy of Documents, Written Notifications, Charters, and Contracts, Kodeks ob administrativnykh narusheniyakh Rossiiskoi Federatsii [Code of Administrative Violations of the Russian Federation]. Available at: http://www.kodap.ru/razdel-2/glava-13/st13-23-koap-rf (accessed 16.10.2018) (in Russ.).

14. Declaration on the Legal Deposit Copy of Printed Publications in Electronic Form, Rossiiskaya gosudarstvennaya biblioteka [Russian State Library]. Available at: https://www.rsl.ru/ru/allnews/neb-oe-declaration (accessed 16.10.2018) (in Russ.).

15. Zotov P.A. Conception of the Legal Deposits System, Bibliografiya i knigovedenie [Bibliography and Bibliology], 2018, no. 3, pp. 5-18 (in Russ.).

16. Lariviere J. Guidelines for Legal Deposit Legislation. Moscow, Pashkov Dom Publ., 2002, 88 p. (in Russ.).

17. Natsional'naya knizhnaya palata Belarusi [National Book Chamber of Belarus]. Available at: https://natbook.org.by/ (accessed 16.10.2018).

18. Sukhorukov K.M. Legal Deposit Copy of Documents Today and Tomorrow, Bibliografiya $i$ knigovedenie [Bibliography and Bibliology], 2018, no. 3, pp. 3-4 (in Russ.).

19. National Projects: Current State and Development Prospects: Plenary Discussion Proceedings, VIII Vserossiiskaya nauchno-prakticheskaya konferentsiya "Fondy bibliotek $v$ tsifrovuyu epokhu: traditsionnye i elektronnye resursy, komplektovanie, ispol'zovanie", 26-30 marta 2018 g., Sankt-Peterburg: materialy [Proceedings of the 8th All-Russian Scientific-Practical Conference "Library Collections in the Digital Age: Traditional and Electronic Resources, Acquisition, and Use" (March 26-30, 2018, St. Petersburg)]. Available at: http:// nlr.ru/tus/20180326/program.html (accessed 28.06.2018) (in Russ.). 